\title{
Infected Walled-Off Pancreatic Necrosis Treated with Multiple-Gateway EUS-Guided Drainage
}

\author{
Margarida Flor de Lima Nuno Nunes Carolina Chálim Rebelo \\ Diogo Bernardo Moura Ana Catarina Rego Maria Antónia Duarte \\ Gastroenterology Department, Hospital do Divino Espírito Santo de Ponta Delgada, Ponta Delgada, Portugal
}

\section{Keywords}

Acute pancreatitis · Walled-off necrosis · Endoscopic ultrasound-guided drainage · Direct endoscopic necrosectomy

\section{Necrose organizada pancreática infetada: abordagem terapêutica por ecoendoscopia}

\section{Palavras Chave}

Pancreatite aguda $\cdot$ Necrose organizada Drenagem guiada por ecoendoscopia · Necrosectomia endoscópica direta

A 74-year-old male patient presented with epigastric pain radiating to the back, nausea, and vomiting. Laboratory tests revealed elevated amylase $(873 \mathrm{U} / \mathrm{L})$, and abdominal ultrasound confirmed the presence of gallstones. Mild lithiasic acute pancreatitis was established in the first $48 \mathrm{~h}$ according to the revised Atlanta classification.

Fig. 1. a EUS showing a 14-cm, walled-off pancreatic necrosis (week 4). b A complex peripancreatic collection surrounding the head, body, and tail of the pancreas, and containing gas, fluid, and necrotic pancreatic tissue on the unciform process on an abdominal CT scan (week 2).

karger@karger.com www.karger.com/pjg

Karger $\stackrel{2}{\%}$ BOPEN ACCESS

\section{(c) 2021 Sociedade Portuguesa de Gastrenterologia} Published by S. Karger AG, Basel

This is an Open Access article licensed under the Creative Commons Attribution-NonCommercial-4.0 International License (CC BY-NC) (http://www.karger.com/Services/OpenAccessLicense), applicable to the online version of the article only. Usage and distribution for commercial purposes requires written permission.
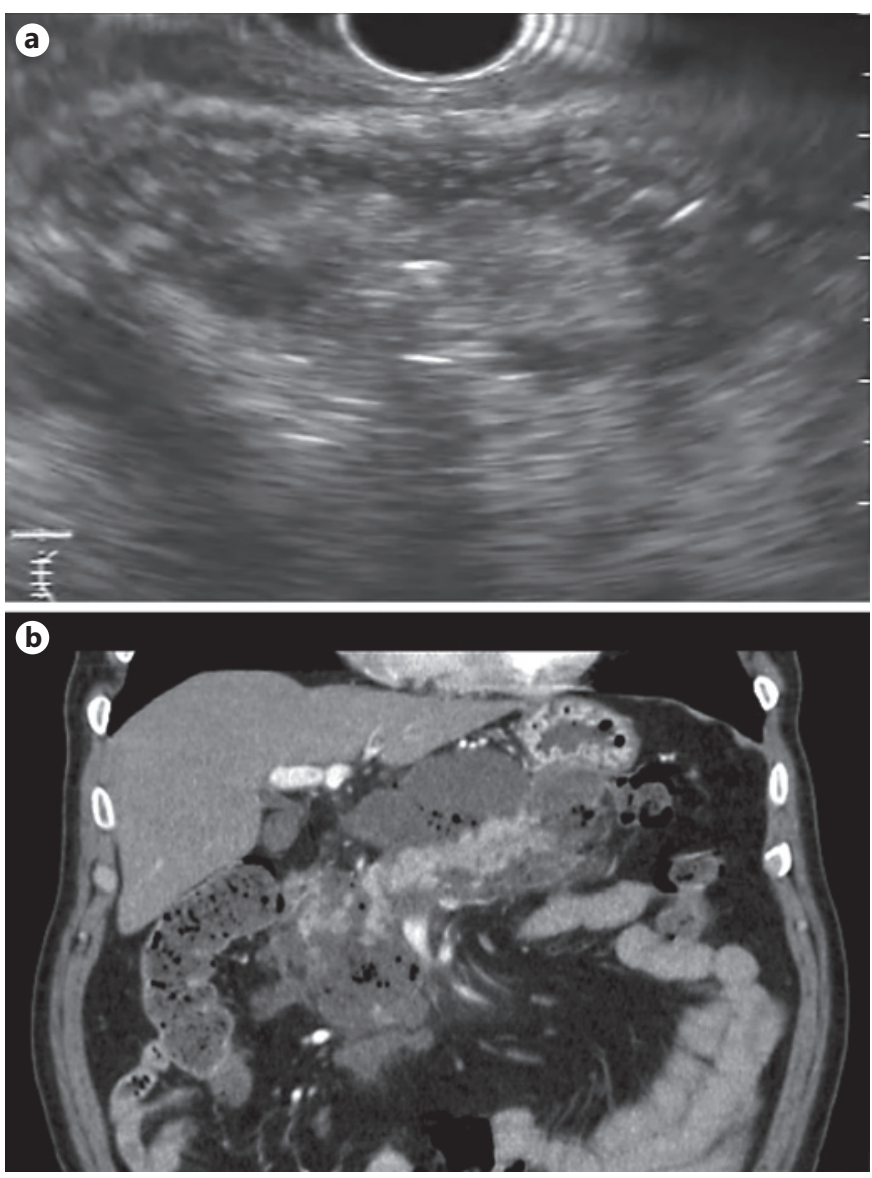

Margarida Flor de Lima Avenida D. Manuel I Matriz

PT-9500-370 Ponta Delgada (Portugal) margaridaflordelima@ hotmail.com 

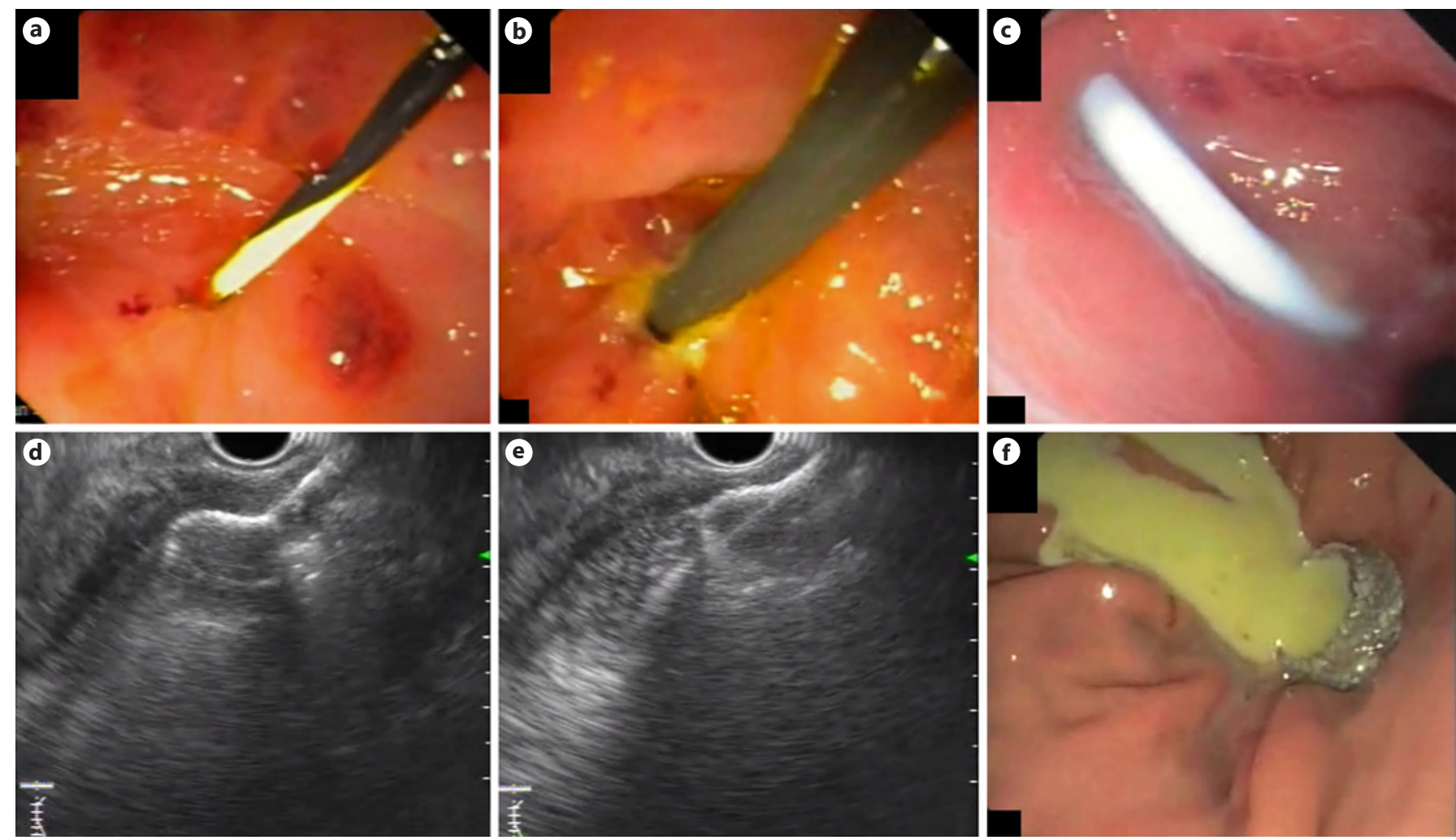

Fig. 2. Primary endoscopic procedure. a Guidewire insertion after direct EUS-guided transgastric puncture of the pyloric antrum. b A cystotome was used to dilate and create access. c Placement of a plastic double-pigtail stent. d, e EUS-guided deployment of the distal flange of LAMS. $\mathbf{f}$ Endoscopic view of the correctly placed LAMS exhibiting pus drainage.

However, during the second week in hospital, the patient showed persisting vomiting and fever. An abdominal computed tomography (CT) scan displayed a complex peripancreatic collection surrounding the head, body, and tail of the pancreas, that contained gas, fluid, and necrotic pancreatic tissue on the unciform process (Fig. 1). Infected necrotizing acute pancreatitis was diagnosed, and broad-spectrum antibiotics were started. Invasive drainage intervention was considered, bearing in mind the clinical evolution and the necessity of a well-defined collection wall.

After 4 weeks, the patient maintained the initial symptoms, although clinically stable and without organ failure, under optimal medical therapy. CT scan and endoscopic ultrasound (EUS) revealed a $14-\mathrm{cm}$, infected, walled-off pancreatic necrosis (WON), with a well-circumscribed wall and a mixed solid (estimated 70\%) and liquid content (Fig. 1). Considering the size of the collection, EUS-guided drainage was performed by a multiple transluminal gateway technique (MTGT), using a linear echoendoscope (GF-UCT180, Olympus, Tokyo, Japan) (Fig. 2). At first, a plastic double-pigtail stent $(8.5 \mathrm{Fr} / 6 \mathrm{~cm})$ was placed on the pyloric antrum, through direct transgastric puncture with a $19-\mathrm{G}$ needle, followed by a 0.035 -inch guidewire insertion. A 6-Fr cystotome was used to dilate and create access. Following plastic stent deployment, minor purulent drainage was observed. Taking into account the size of the collection, the prospect of insufficient drainage and the future possibility of a direct transluminal endoscopic necrosectomy (DEN) being performed, a second stent, a lumen-apposing metal stent (LAMS) (Hot AXIOS $^{\mathrm{TM}}, 15 \times 10 \mathrm{~mm}$, Boston Scientific, Marlborough, MA, USA) was positioned through the gastric body during the same intervention, followed by abundant pus drainage. Acknowledging adequate primary drainage in a clinically stable patient, a nasocystic catheter was not placed.

After the procedure, the patient showed partial clinical improvement, maintaining intermittent epigastric discomfort, nausea, and early satiety.

Six weeks later, a secondary endoscopic intervention using a gastroscope (GIF-H190, Olympus, Tokyo, Japan) 

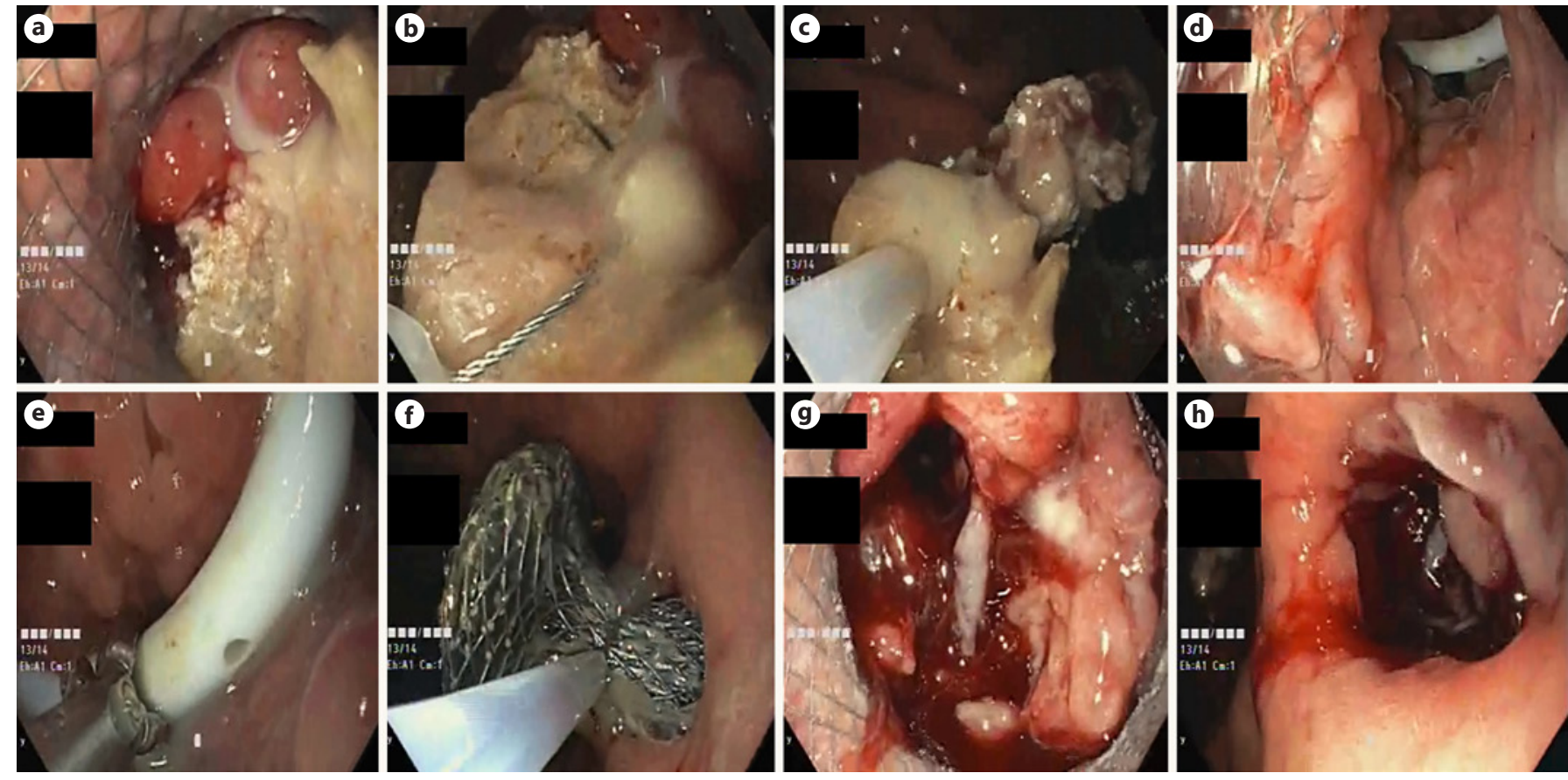

Fig. 3. Secondary endoscopic procedure. a Endoscopic view through the previously placed LAMS of the necrotic tissue inside of the peripancreatic collection. $\mathbf{b}, \mathbf{c}$ Direct transluminal endoscopic necrosectomy using a snare. d Endoscopic view of the inside of the collection after removal of the necrotic debris, revealing communication between the 2 placed stents. e Plastic stent removal using a rat-tooth grasping forceps. $f$ LAMS removal using a snare. $\mathbf{g}$ Endoscopic view of the inside of the collection after removal of necrotic debris and the plastic stent. h Endoscopic gastric view after LAMS removal.

allowed the removal of all the necrotic debris via DEN, with a water-pump system irrigation and a snare (Fig. 3). The stents were removed during the procedure using rattooth grasping forceps for the plastic stent and a snare for the LAMS.

The patient was followed up at another hospital and was only transferred to perform endoscopic procedures. An earlier timing of the second procedure was initially programmed, but was delayed by logistical interhospital arrangements.

Drainage and/or debridement is recommended for patients with acute necrotizing pancreatitis and infected necrosis $[1,2]$. EUS-guided drainage has been increasingly used to treat infected WON, involving transmural placement of plastic or self-expandable metal stents [1-3]. The use of LAMS, besides allowing further DEN, possibly contributes to more efficient drainage, with less and shorter procedures [3]. MTGT aims to ease the drainage and minimize the number of necrosectomies, especially in large and multiple WON or when there is an otherwise suboptimal response [1, 4-5].

\section{Statement of Ethics}

Written informed consent was obtained from the patient. This study did not require review/approval by the appropriate ethics committee.

\section{Conflict of Interest Statement}

The authors have no conflicts of interest to declare.

\section{Funding Sources}

There was no funding.

\section{Author Contributions}

M.F.d.L.: article concept, literature review, and drafting of the manuscript. N.N.: main endoscopist of the described procedure, literature review and critical review of the manuscript. C.C.R., D.B.M., A.C.R., and M.A.D.: critical review of the manuscript. 


\section{References}

1 Arvanitakis M, Dumonceau JM, Albert J, Badaoui A, Bali MA, Barthet M, et al. Endoscopic management of acute necrotizing pancreatitis: European Society of Gastrointestinal Endoscopy (ESGE) evidence-based multidisciplinary guidelines. Endoscopy. 2018 May; 50(5):524-46.
2 Baron TH, DiMaio CJ, Wang AY, Morgan KA. American Gastroenterological Association Clinical Practice Update: Management of Pancreatic Necrosis. Gastroenterology. 2020 Jan;158(1):67-75.e1.

3 Chen YI, Yang J, Friedland S, Holmes I, Law $\mathrm{R}$, Hosmer A, et al. Lumen apposing metal stents are superior to plastic stents in pancreatic walled-off necrosis: a large international multicenter study. Endosc Int Open. 2019 Mar;7(3):E347-54.
4 Varadarajulu S, Phadnis MA, Christein JD, Wilcox CM. Multiple transluminal gateway technique for EUS-guided drainage of symptomatic walled-off pancreatic necrosis. Gastrointest Endosc. 2011 Jul;74(1):74-80.

5 Mukai S, Itoi T, Moriyasu F. Interventional endoscopy for the treatment of pancreatic pseudocyst and walled-off necrosis (with videos). J Hepatobiliary Pancreat Sci. 2014 Oct; 21(10):E75-85. 